\title{
ANHYDROUS YELLOW FERRIC OXIDE
}

\author{
BY JOHN H. YOE
}

\section{Introduction}

Ordinary ferric oxide is dark red in color, and when it is finely ground and diluted with finely ground, white materials, a series of mixtures is obtained of varying shades of pink. The indications are, however, that very fine particles of ferric oxide are yellow in color. Thus Keane ${ }^{1}$ considered the yellow color of bricks to be due to finely divided ferric oxide whose agglomeration had been prevented by the presence of alumina and perhaps other substances. He also concluded that the so-called Mars pigments owe their yellow color to finely divided ferric oxide, stabilized by hydrous aluminum oxide. When these pigments are dehydrated they turn red, as the alumina is not present in sufficient quantity to prevent agglomeration of the ferric oxide. Keane also suggested that it should be possible to obtain a mixture of ferric and aluminum hydroxides which would remain yellow on heating.

Scheetz ${ }^{2}$ carried out experiments to test this point. He prepared solutions of ferrous sulphate and aluminum sulphate in such proportions that after precipitation and oxidation they would give a product containing between 2 percent and 20 percent of ferric oxide. These solutions were treated with sodium carbonate, sodium hydroxide, and calcium hydroxide, respectively; the precipitates being washed, dried gradually, and finally heated to about $1000^{\circ} \mathrm{C}$. With sodium carbonate and sodium hydroxide, non-uniform products of varying color were obtained. With calcium hydroxide, however, a series of products was obtained that varied in color from pale yellow ( 2 percent $\mathrm{Fe}_{2} \mathrm{O}_{3}$ ) to chocolate-brown (20 percent $\mathrm{Fe}_{2} \mathrm{O}_{3}$ ), all products containing less than eight percent of ferric oxide being uniformly yellow or buff. Since the mix-

1 Jour. Phys. Chem., 20, 734 (I916)

2Ibid., 2I, 570 (1917). 
tures prepared in this way contained calcium sulphate in addition to the ferric and aluminum oxides, Scheetz was unable to show whether the stabilization of the yellow oxide was due entirely to the alumina, or whether the calcium sulphate played an important part.

The experiments described in the present article represent an extension of the work of Scheetz designed to indicate more definitely the nature of the stabilizing agent, and also an attempt to prepare anhydrous ferric oxide free from stabilizing agent.

\section{Experimental}

(1) Aqueous solutions of ferrous and aluminum salts were put in 2-liter, glass-stoppered bottles, and were precipitated with calcium, barium, or ammonium hydroxide, the reagent being added gradually, and the mixtures being shaken thoroughly after each addition. After complete precipitation the hydroxide mixtures were washed by decantation and filtered with the aid of suction. They were dried at $100^{\circ}$ and finally heated to about $1000^{\circ}$, the temperature being increased gradually. The anhydrous products were ground in an agate mortar and were screened through a i5o-mesh screen. In each case the product was lighter in color after grinding, the color growing lighter with decrease in the size of the particles. This is in accord with the work of Wöhler and Condrea, ${ }^{1}$ and that of Weiser. ${ }^{2}$ The results are summarized below. The color was always iniform unless otherwise indicated.

The experiments with calcium hydroxide upon solutions of ferrous and aluminum sulphates confirm Scheetz' results. The experiments with barium hydroxide show that similar mixtures containing barium sulphate instead of calcium sulphate likewise contain stable yellow ferric oxide.

The experiments with calcium hydroxide upon solutions of the chlorides show that the presence of calcium sulphate is not essential to the stabilization. It should, however, be

${ }^{1}$ Zeit. angew. Chem., 2I, 48 (1908).

${ }^{2}$ Jour. Phys. Chem., 24, 277 (1920). 
TABLE I

Oxides precipitated from Solution of the Sulphates, by

\begin{tabular}{r|l|l|l}
\hline$\% \mathrm{Fe}_{2} \mathrm{O}_{3}$ & \multicolumn{1}{|c|}{$\mathrm{Ca}(\mathrm{OH})_{2}$} & \multicolumn{1}{|c|}{$\mathrm{Ba}(\mathrm{OH})_{2}$} & \multicolumn{1}{|c|}{$\mathrm{NH}_{4} \mathrm{OH}$} \\
\cline { 1 - 3 } $\mathrm{I}$ & & Pale yellow $(a)$ & \\
2 & Yellow tinge & Yellow $(b)$ & \\
3 & Cream & Buff $(c)$ & Yellow \\
4 & Buff & \\
6 & Light brown & & Brown \\
8 & Brown & & Reddish brown \\
IO & Brown (darker) & & \\
I5 & Reddish brown & &
\end{tabular}
$\mathrm{BaSO}_{4}$.

(a) Mixture contains I percent $\mathrm{Fe}_{2} \mathrm{O}_{3}$, 10 percent $\mathrm{Al}_{2} \mathrm{O}_{3}, 89$ percent $\mathrm{BaSO}_{4}$

(b) Mixture contains 3 percent $\mathrm{Fe}_{2} \mathrm{O}_{3}$, Io percent $\mathrm{Al}_{2} \mathrm{O}_{3}, 87$ percent $\mathrm{BaSO}_{4}$

(c) Mixture contains 6 percent $\mathrm{Fe}_{2} \mathrm{O}_{3}$, ro percent $\mathrm{Al}_{2} \mathrm{O}_{3}, 84$ percent

TABLE II

Oxides precipitated from Solution of the Chlorides, by

\begin{tabular}{|c|c|c|c|}
\hline$\% \mathrm{Fe}_{2} \mathrm{O}_{3}$ & $\mathrm{Ca}(\mathrm{OH})_{2}$ & $\mathrm{Ba}(\mathrm{OH})_{2}$ & $\mathrm{NH}_{4} \mathrm{OH}$ \\
\hline 2 & Pale yellow & & Pale yellow \\
\hline 4 & & Dull brown & Yellow \\
\hline 6 & Buff & $\begin{array}{c}\text { Dull brown } \\
\text { (darker) }\end{array}$ & Light brown \\
\hline 8 & & & Light brown \\
\hline ro & Dull light brown & & Brown \\
\hline I 5 & & & Reddish brown \\
\hline 20 & Chocolate & & $\begin{array}{l}\text { Reddish brown } \\
\text { (darker) }\end{array}$ \\
\hline
\end{tabular}

noted that in certain experiments not here recorded pink mixtures were obtained when calcium hydroxide was added to solutions of ferrous and aluminum chlorides, indicating that agglomeration is not invariably prevented.

The experiments with ammonium hydroxide upon solutions of both sulphates and chlorides show that yellow mixtures may be obtained in which ferric oxide and aluminum 
oxide are the only components, thus showing that alumina may act as an effective stabilizing agent for finely divided yellow ferric oxide.

(2) In order to determine whether $\mathrm{CaSO}_{4}$ or $\mathrm{BaSO}_{4}$ could act as stabilizing agent, experiments were carried out in which solutions of ferrous sulphate, containing in some cases an excess of potassium sulphate, were precipitated by means of calcium or barium hydroxide. These experiments showed that when a quite large excess of $\mathrm{CaSO}_{4}$ or $\mathrm{BaSO}_{4}$ is precipitated with the ferric hydroxide, agglomeration of the ferric oxide may be prevented. For example, a product containing 6 percent $\mathrm{Fe}_{2} \mathrm{O}_{3}$ and 94 percent $\mathrm{BaSO}_{4}$ was a uniform light buff, similar in color to the mixtures obtained in the presence of alumina. With smaller excesses of sulphate, however, reddish brown mixtures were usually obtained.

(3) Experiments were also conducted with the object of preparing a stabilized anhydrous ferric oxide, and then dissolving out the stabilizing agent. Thus a solution of ferrous and aluminum chlorides, in such proportions that after dehydrating the hydroxides the mixture would contain 8 percent $\mathrm{Fe}_{2} \mathrm{O}_{3}$ and 92 percent $\mathrm{Al}_{2} \mathrm{O}_{3}$, was precipitated by ammonium hydroxide. The precipitated hydroxides were dried in vacuum at $100^{\circ}$ for ten hours. The apparently dry material was then removed from the flask, ground in an agate mortar, and covered with cold sodium hydroxide, different concentrations of sodium hydroxide being used in different experiments. The mixtures were allowed to stand at room temperature. At the end of twenty-four hours the aluminum hydroxide had been largely dissolved, but the residue had changed in color to a dark reddish brown, indicating that agglomeration of the ferric oxide had taken place.

\section{Summary}

Anhydrous yellow ferric oxide has been obtained in mixtures with (a) alumina, (b) calcium sulphate, (c) barium sulphate, (d) alumina and calcium sulphate, (e) alumina and 
barium sulphate. The results confirm and extend the work of Scheetz.

Attempts to remove the stabilizing agent (e. g. by dissolving the alumina with $\mathrm{NaOH}$ ) resulted invariably in an agglomeration of the ferric oxide, with a corresponding change of color from yellow to red.

University of Virginia

October, Ig2o 